\title{
Simplification options for more efficient using of Angular and Linear measuring Rules for Fire Control
}

\author{
Martin Blaha, Ladislav Potužák, Michal Šustr, Jan Ivan, Tomáš Havlík \\ University of Defence in Brno, \\ Brno, 66210 \\ Czech Republic
}

Received: December 13, 2020. Revised: February 26, 2021. Accepted: March 9, 2021.

Published: March 12, 2021.

\begin{abstract}
The Army of the Czech Republic is part of a broad military (security) alliance (such as NATO, EU, UN), and is deployable both on its territory, but also on the territory of the states of the members of the alliance, or anywhere in the world. The article focuses on inference of principles and limits for more efficient using of mile rule in school and combat condition. The Linear and Angular issues (which contains mile rule) in perspective Artillery Fire Control System called PVNPG-14M are the important area of the present defence research of Fire Support Department of University of Defence in Brno.

The efficient using of artillery rules is necessary condition for the case without automated command, control, and information systems. Only under conditions of comparable efficiency can tasks of the required quality be fulfilled in the event of a malfunction of the automated system. Decision-making processes carried out by the commanders in the present and in the upcoming future depend on the correct application of the presented rules. The paper defines appropriate Linear and Angular variables for common use by Artillery and Mechanized commanders.

The presented results are based on the analysis performed in the classroom and at the same time during live combat exercises.
\end{abstract}

Keywords-Artillery, mile, Decision-making process, software development, Command, Control and Information System, C2I.

\section{INTRODUCTION}

$\mathrm{T}$ HE Czech Field Artillery is a part of Czech ground forces within the organizational structure and plays an irreplaceable role of fire support of supported units. Artillery cannons and mortars support mechanized units primarily by artillery fire from hidden firing positions.

Its main task is to eliminate the enemy's targets by effective artillery firing, which greatly reduces the loss of their own forces and equipment. When attacking their own Artillery gun systems, the artillery is able to fire also by direct firing on enemy combat vehicles. [1]

The required efficiency of artillery fire can be achieved with highly accurate fire with sufficient surprise. The basic precondition for high surprise is, above all, the early start of firing at the target. To fulfill this premise of surprising and timely artillery fire, it is necessary to quickly determine the initial fire elements of the artillery firing and the associated coefficients for firing.

Calculation of the fire elements is a lengthy process based on the mathematical apparatus of several disciplines such as Ballistics, Meteorology, Geography and Theory of probability. Automation of the entire process of calculation of fire elements accelerates and reduces the likelihood of errors. [2]

With the same purpose - effective and accurate firing is created automated software for preparing artillery fire elements for firing. This use of the new software will create a control mechanism that will facilitate the user's calculations and the correct application of all artillery principles and rules. The need for follow-up control is necessary because of the huge extent of the effects of artillery fire. Control calculations must precede each artillery fire.

The primary artillery fire control system is currently out of date and unused, and the acquisition of a new fire control system is being prepared. Now is the right time to create a substitute and control artillery fire control system that meets the above requirements.

Application architecture describes the following Figure 1.

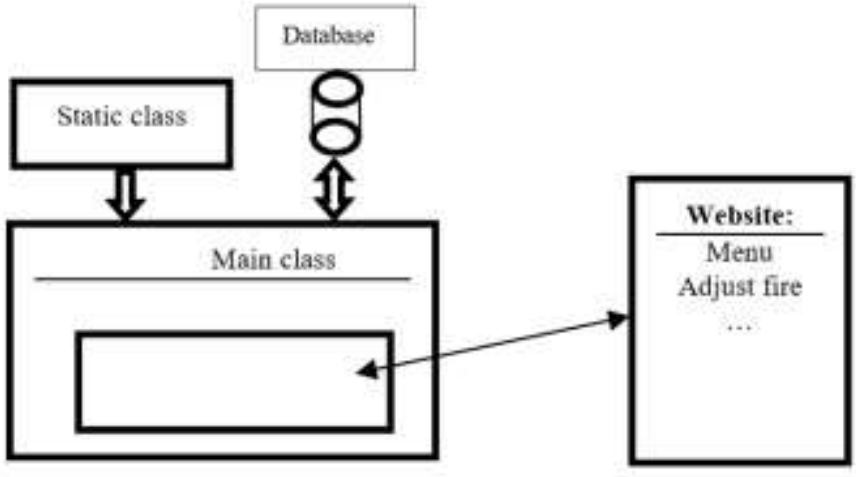

Fig. 1 Scheme of architecture of PVNPG-14M

In order for the prepared system to be fully functional, it is necessary to fulfill the artillery principles and respect the 
artillery rules. These rules are used in the classic (manual) methods of preparing artillery fire elements. The new application must be open to user changes, updates, use a common programming language and, last but not least, be supported by the windows system (which is official for the Army of the Czech Republic).

It is important to calculate the necessary fire input elements for artillery fire in the available time and with adequate accuracy. In the battlefield, it is advisable to quickly calculate distances, lengths, heights and angles by using a clear artillery rule. Using of a simplified artillery rule is typical not only for artillery commanders, but also for commanders of mechanized units. To use the rule correctly, you need to know the nature of the rule and the restrictions on its application.

Nowadays, the size of a mile is not standardized in NATO armies (a circle can consist of 6000 mill's segment, but it is also possible to divide a circle into 6400 mill's segment or 6300). However, the number of mills in the circle is being unified gradually via the Czech army. With this standardization, optical artillery protractors, artillery means or, for example, artillery weapons are gradually being modernized. However, the correct use of new artillery means is conditioned by the correct application of the artillery rule, including its restrictions. That is the reason to authors to solve the issue of right using the artillery rule based on new size of mills.

\section{MATHEMATICAL DEFINITION OF ARTILLERY ANGULAR MEASURES}

Mathematical-arithmetic procedures are typical for solving artillery fire problems in combat conditions. In such cases, angular and longitudinal values are recalculated. A relevant study can be found in [3].

More used under standard conditions are angular units - degrees, minutes and seconds. However, these units are impractical in combat conditions. In their case, it is necessary to convert degrees to minutes and minutes to seconds. In the condition of Czech artillery, a specific angular measures "dílec" (dc; 6000 segment in circle) or "mil" (6400 segment in circle) are used (Figure 2, 3).

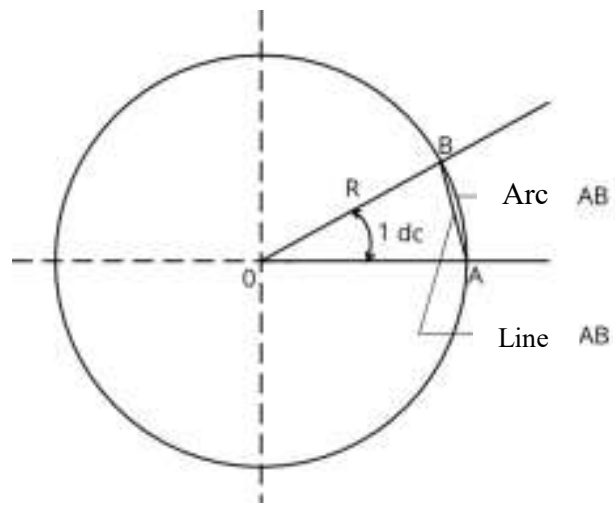

Fig. 2 Graphic display of Artillery angular measures - dc
The "dílec" (dc) is defined as a centre angle which is below the line (arc) of approximately $1 \mathrm{~m}(1.05 \mathrm{~m})$ long at a distance of $1 \mathrm{~km}$. The "dílec" corresponds to the 1/6000 length of the arc of the circle. The whole circle is therefore divided into 6000 segments (60-00). [1]

On Figure 2 there is line the $A B$, which is one meter and in this picture chord with a circle corresponds $A B$ curve that is slightly longer.

The arc $\mathrm{AB}$ length:

$$
\widehat{\mathrm{AB}}=\frac{2 \pi R}{6000} \cdot \alpha,
$$

because $\quad \alpha=1 d c$,

$\overparen{\mathrm{AB}}=\frac{2 \pi R}{6000} \doteq \frac{6,28}{6000} \cdot \mathrm{R} \doteq \frac{1}{955} \mathrm{R} \doteq 0,0010472 \mathrm{R}$

after putting $\quad \mathrm{R}=1000 \mathrm{~m}$,

$$
\widehat{\mathrm{AB}} \doteq 1,0472 m \doteq 1,05 m
$$

The difference of the length for the line $\mathrm{AB}$ and arc $\mathrm{AB}$ is about 0.05 meters, which equivalent to $5 \%$.

The value of mil is exactly the center angle that is below the line of approximately 0,1 meters at a length distance of 100 meters.

For artillery battlefield using, the definition is more favorable: mil is the central angle as below a line (arch) of approximately $1 \mathrm{~m}(0.98 \mathrm{~m})$ at a length distance of $1 \mathrm{~km}$. One mil corresponds to $1 / 6400$ of arc length of the circle. The full circle is thus divided into 64-00 miles (6400). In this case the one-meter line $(A B)$ is a part of the tangent to the circle and displays to the curve $\mathrm{CD}$, which is slightly shorter (Figure 3).

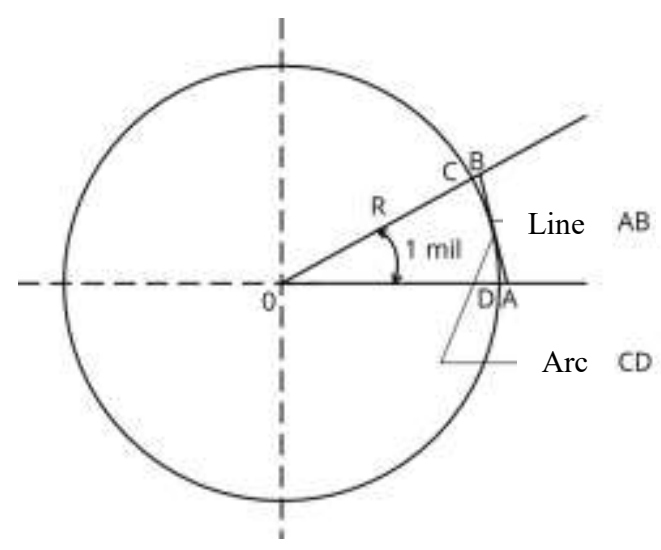

Fig. 3 Graphic display of Artillery angular measures - mil 
The arc's length of the CD:

$$
\overparen{C D}=\frac{2 \pi R}{6400} \cdot \alpha,
$$

because $\quad \alpha=1 \mathrm{mil}$,

$$
\begin{aligned}
& \overparen{C D}=\frac{2 \pi R}{6400}=\frac{6,28}{6400} \cdot R=\frac{1}{1019} \cdot R=0,0009812 R \\
& \text { after putting } \quad \mathrm{R}=1000 \mathrm{~m},
\end{aligned}
$$

$$
\overparen{C D}=0,9812 m=0,98 m
$$

According to the above formulas, the arc $\mathrm{CD}$ is exactly 0.02 meters smaller than the line $\mathrm{AB}$. This corresponds to $2 \%$. The difference in the distance of the arc is equal to $1 / 1000$ of the radius of the circle, which represents one segment, that is one mile.

It is possible to convert miles per part using the conversion coefficient 15/16 (6000/6400) and reverse in a similar way $16 / 15$.

In order to achieve clarity and at the same time maximum simplification, artillery experts applied the rule of writing and reading values. Hundreds of mil end with a hyphen, followed by tens and units of mil. The table below provides typical examples of the application of this rule (Table 1).

Table 1 Rules of typing Artillery measures

\begin{tabular}{|c|c|}
\hline Artillery angular (mil) & typing \\
\hline 4765 & $47-65$ \\
\hline 3804 & $38-04$ \\
\hline 5200 & $52-00$ \\
\hline 91 & $0-91$ \\
\hline 6 & $0-06$ \\
\hline 0 & $0-00$ \\
\hline
\end{tabular}

Because 6000 (6400) segments (miles) correspond to an angle of $360^{\circ}$, the value of one segment (mil) in angular minutes is:

$$
\begin{aligned}
& 0-01=\frac{360^{\circ}-60}{6000(6400)}=3,6^{\prime}\left(3,375^{\prime}\right) \\
& 100 \mathrm{dc}=360^{\prime}=6^{\circ} \\
& 100 \mathrm{mil}=337,5^{\prime}=5^{\circ} 37^{\prime} 30^{\prime \prime}
\end{aligned}
$$

If denotes the angle " $n$ " in segments (miles) and " $\alpha$ " the same angle in angular minutes, the following holds:

$$
\alpha=3,6^{\prime}\left(3,375^{\prime}\right) \cdot \mathrm{n}
$$

$$
\mathrm{n}=\frac{\alpha}{3,6^{l}\left(3,375^{J}\right)}
$$

One degree is:

$$
\begin{aligned}
& 1^{\circ}=\frac{6000}{360^{\circ}} \doteq 16,67 \doteq 16,7 d c \\
& 1^{\circ}=\frac{6400}{360^{\circ}} \doteq 17,78 \doteq 17,8 \mathrm{mil}
\end{aligned}
$$

To convert the "dílec" (mil) to degrees and minutes and vice versa, calculators are used, pre-compiled tables usually listed in the artillery firing tables, in the past nomograms compiled for the range $0-00$ to $1-00$ were used.

\section{RELATIONSHIP BETWEEN ANGULAR AND LINEAR VALUES}

If in the isosceles triangle "MON" the distance "l" corresponds to the distance between $\mathrm{M}$ and $\mathrm{N}$ (center "S"), then this distance will correspond to the angle $\alpha$, which is at the line $\mathrm{d}$ or $\mathrm{d} 1$ from the observation point "O" to the point "S" as shown in Figure 4.

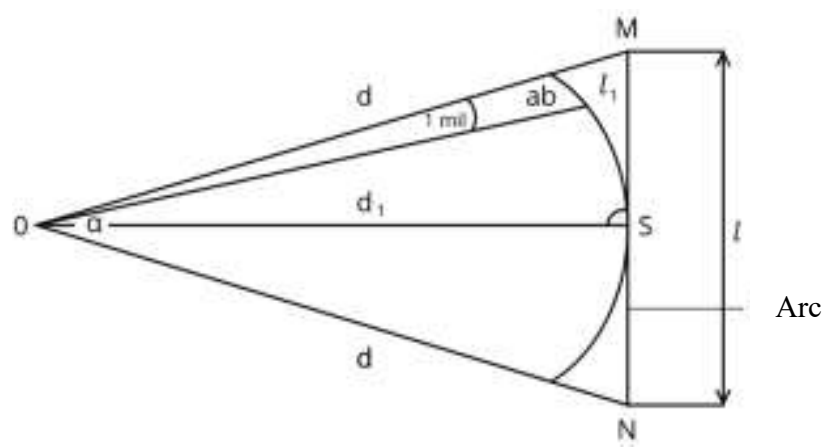

Fig. 4 Relationship between Linear and Angular values of mil

According to the formula below, it can be stated that one mile corresponds to the length of the arc:

$$
\begin{aligned}
& l_{1}=0,0009812 \mathrm{R} \\
& l_{1} \doteq 0,001 \mathrm{~d}
\end{aligned}
$$

Due to the generally applicable rules in a right-angled triangle the trigonometric functions can be applied:

$$
l=d \cdot 2 \cdot \sin \frac{\alpha}{2}=d_{1} \cdot 2 \cdot \operatorname{tg} \frac{\alpha}{2}
$$

Because the triangle $\mathrm{MON}$ is right-angled, Figure 5, the line $\mathrm{MO}$ is perpendicular to the line $\mathrm{MN}$. The distance of the line "l" can be seen in practice at angles $\alpha$ (these are usually very small):

$$
l=d \cdot \sin \alpha\left(=d_{1} \times \operatorname{tg} \alpha\right)
$$




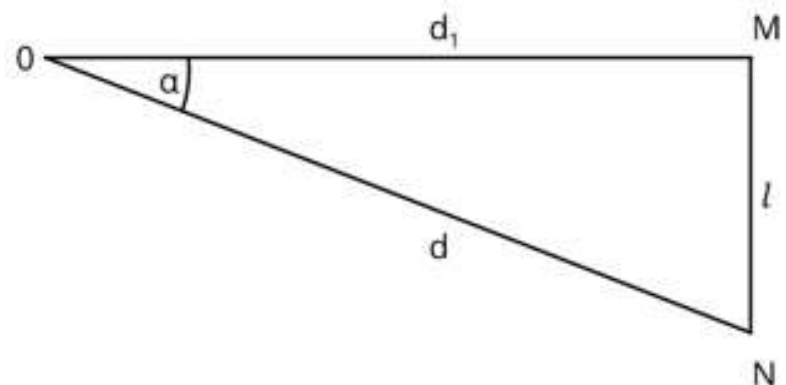

Fig. 5 Determination of length 1 from rectangular triangle

Formulas (3), (4) are not practical in battlefield practice because their use requires knowledge of trigonometric functions. [1] [5] [6]

Between the length "l" and the distance "d" exists for the angle dependence of the size of about 1 mil. From the previous equations can therefore derive the following:

$\sin 0-01=\operatorname{tg} 0-01=2 \sin \frac{0-01}{2}=2 \operatorname{tg} \frac{0-01}{2}=0,0010472$

The same conclusion can be drawn from the formula (2).

From the previous derivations, the length of the arc $\mathrm{AB}$ can be determined according to the formula $1_{1}=0,0010472 \mathrm{R}=$ $=0,001 \mathrm{R}(2)$ or it is equally possible to make this conclusion from Figure 4, and after rounding gets to one thousandth it gets:

$$
l_{1}=0,001 \mathrm{~d}
$$

Overall, it is possible to evaluate the distance to the object, the length of the arc and the angle at which the object is observed using the following formulas:

$$
\begin{aligned}
& \mathrm{MN}=l_{1} \cdot \alpha \\
& \mathrm{MN}=0,001 \mathrm{~d} \cdot \alpha \\
& \mathrm{MN} \doteq l=0,001 \mathrm{~d} \cdot \alpha
\end{aligned}
$$

Formula (22) is applicable for many military-practical tasks in many sub-areas. The formula is designed to allow the calculation of the third value from two others known values:

1) from the formula it is possible to calculate the unknown value - height, when two known values angle to object and distance to object (e.g. the width of the target):

$$
l=\alpha \cdot \frac{d}{1000}=\alpha \cdot 0,001 \mathrm{~d}
$$

2) it is possible to calculate the angle $\alpha$ in mil to an object if the values of the distance to the object and the height of the object are known:

$$
\alpha=\frac{1000-l}{d}=\frac{l}{0,001 d}
$$

3) the third variant is a situation where the distance to the object is known and at the same time the angle in mil at which the object can be observed is known, then it is possible to calculate the distance to the object:

$$
\begin{aligned}
& \mathrm{d}=\frac{1000-l}{\alpha} \\
& 0,001 \mathrm{~d}=\frac{l}{\alpha}
\end{aligned}
$$

The combined use of these formulas in artillery practice is called the artillery rule.

The main advantage of formula (5) based on practicality and speed calculate practical tasks in combat conditions. These formulas are very useful, but they contain some simplification and the final error increases as the angle $\alpha$ increases.

To assess the degree of assumption, it is necessary to assess the right parts of formulas (4) and (5), which form the basis of the artillery rule:

$$
\frac{d \cdot \alpha}{1000} \doteq d \cdot \sin \alpha
$$

From (27) we get : $\alpha \doteq 1000 \times \sin \alpha$

Formula (22) is limited in accuracy according to the dependence on accuracy of equations (27) and (28) based on the magnitude of the angle $\alpha$. The specific errors $(\Delta)$ resulting from equations (27) and (28) are calculated and summarized in Table 2:

$$
\begin{aligned}
& \Delta^{\prime}=\alpha-1000 \times \sin \alpha \\
& \Delta^{\prime \prime}=\alpha-1000 \times \operatorname{tg} \alpha
\end{aligned}
$$

Furthermore, relative errors $(\delta)$ are calculated for specific lengths "1" based on the formulas below:

$$
\begin{aligned}
& \delta^{\prime}=\frac{\frac{d \times \alpha}{1000}-d \times \sin \alpha}{d \times \sin \alpha}=\frac{\alpha-1000 \cdot \sin \alpha}{1000 \times \sin \alpha}=\frac{\Delta^{\prime}}{1000 \times \sin \alpha} \\
& \delta^{\prime \prime}=\frac{\frac{d \cdot \alpha}{1000}-d \cdot \operatorname{tg} \alpha}{d \cdot \operatorname{tg} \alpha}=\frac{\alpha-1000 \times \operatorname{tg} \alpha}{1000 \times \operatorname{tg} \alpha}=\frac{\Delta^{\prime \prime}}{1000 \cdot \operatorname{tg} \alpha}
\end{aligned}
$$


Table 2 Equation errors and relative errors of determination of length "l" if the angles $\alpha$ are in the mil

\begin{tabular}{|c|c|c|c|c|c|c|}
\hline \multirow{2}{*}{$d($ mill) } & \multicolumn{3}{|c|}{$l=d-\sin \alpha$} & \multicolumn{3}{c|}{$l=d \cdot$ tga } \\
\cline { 2 - 7 } & $1000-\sin \alpha$ & $\Delta^{\prime}($ mil) & $\delta(\%)$ & $1000-$ tga & $\Delta^{\prime \prime}($ mil) & $\delta^{\prime \prime}(\%)$ \\
\hline $0-01$ & 0,982 & $+0,018$ & $+1,8$ & 0,982 & $+0,018$ & $+1,8$ \\
\hline $0-10$ & 9,82 & $+0,18$ & $+1,8$ & 9,82 & $+0,18$ & $+1,8$ \\
\hline $0-20$ & 19,63 & $+0,37$ & $+1,9$ & 19,64 & $+0,36$ & $+1,8$ \\
\hline $0-50$ & 49,07 & $+0,93$ & $+1,9$ & 49,13 & $+0,87$ & $+1,8$ \\
\hline $1-00$ & 98,02 & $+1,98$ & $+2,0$ & 98,49 & $+1,51$ & $+1,5$ \\
\hline $2-00$ & 195,09 & $+4,91$ & $+2,5$ & 198,91 & $+1,19$ & $+0,6$ \\
\hline $3-00$ & 290,29 & $+9,71$ & $+3,3$ & 303,35 & $-3,35$ & $-1,1$ \\
\hline $4-00$ & 382,68 & $+17,32$ & $+4,5$ & 414,21 & $-14,21$ & $-3,4$ \\
\hline $5-00$ & 471,40 & $+28,6$ & $+6,1$ & 534,51 & $-34,51$ & $-6,5$ \\
\hline
\end{tabular}

From the data presented in Table 2, it is possible to make the following conclusions:

1) Provided that the length value is exactly "l" and is determined by $\sin \alpha$, then the length (distance to the object) "d" is a hypotenuse of the right triangle and the error $\Delta^{\prime}$ resulting from equation (28) has a positive value in the range of angle values from 0 to 500 mil and its absolute value increases up to 28.6 mil. Furthermore, it is possible to derive the relative error $\left(\delta^{\prime}\right)$, assuming the use of formula (22) and determining the length "l", while the error decreases by up to $6.1 \%$

2) Provided that the length value is exactly "l" and is determined by $\operatorname{tg} \alpha$, then the length (distance to the object) " $d "$ is a hypotenuse of the right triangle and the error $\Delta^{\prime \prime}$ resulting from equation (28) has a positive and negativ value in the range of angle values from 0 to 100 mil increase in positive value up to $+1,51 \mathrm{mil}$ and from 200 to $500 \mathrm{mil}$ increases to its absolute value from 1,19 to $34,51 \mathrm{mil}$. The relative error $\left(\delta^{\prime \prime}\right)$ is in positive value from 0 to $100 \mathrm{mil}$ is approximately $1,8 \%$ and from 200 to 500 mil its absolute value equal approximately increases from 0,6 to $6,5 \%$.

Using formula (22) and other formulas derived from it, it is necessary to achieve an error $\Delta$ of up to one mile. Such a deviation is achieved for angles $\alpha$ from 0 to 50 mils, which is the limit value for professional practice.

3 ) In the range of values of angle $\alpha$ from 0 to 100 mils, the relative error $(\delta)$ is up to a maximum of $2 \%$, while the range of distance (length) "d" has no significant effect. This small deviation is derived from the fact that the simplification is accepted that one mile is $1 / 1000$ " $\mathrm{d}$ " and it is not $1 / 1019$ "d" (that means the arc is considered a chord).

In order to be able to use the artillery rule for artillery tasks on the battlefield within 100 mils for $\alpha$, it is necessary to include a $2 \%$ correction as the systematic error. This will eliminate the error in formula (22) and it can be used in normal case.

Finally, it can be stated that based on the analysis of formulas, it is necessary to reduce the resulting value by $2 \%$ to calculate the length "l" (practically this means multiplying the value by 0.98). Similarly, for the values of the angle $\alpha$ and the values of the distance "d", the result must be multiplied by 1.02 (the resulting values must be increased by $2 \%$ ).

\section{EXAMPLES OF USE IN SOFTWARE}

Artillery commanders and staffs must in all circumstances find the most appropriate way to prepare elements for Fire for Effect for artillery firing. Such a variant must be the most accurate, fastest and tactically advantageous in the battlefield circumstances. There are several basic methods and they are different in terms of conditions and overall accuracy. [4] [5]

Under normal circumstances, commanders (artillery unit's commanders or mechanized unit's commanders) learned to make decisions during training. They usually choose simpler methods because they do not have enough information and appropriate application support. If they will be able to use the new PVNPG-14M applications (Figure 8), they will receive quality application support, which is able to perform them in any way of preparing fire elements for artillery firing.

Artillery firing elements for Fire for Effect can be chosen from these methods:

A) Complete preparation - Accurate Predicted Fire (APF);

B) By results from creating fictional auxiliary target;

C) By using an adjustment gun;

D) Abridged preparation;

E) Simplified preparation. [2] [6] [7] [8]

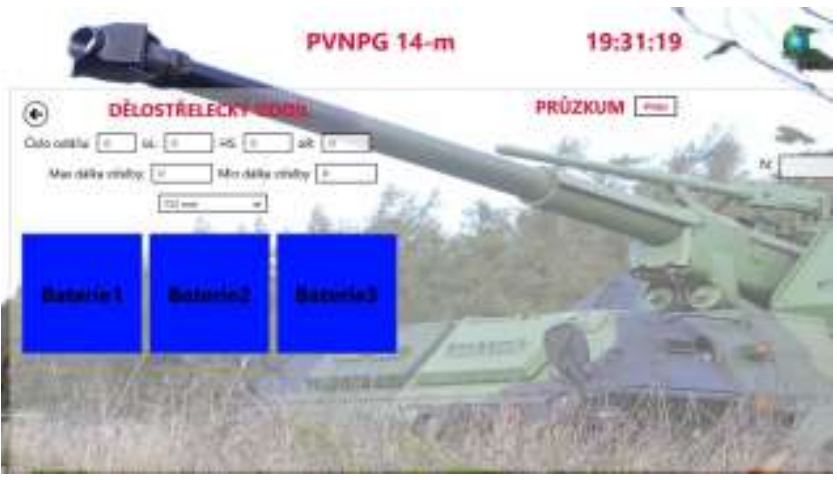

Fig. 8 Print Screen PVNPG-14M

\section{A. Accurate Predicted Fire}

The basic variant is the Complete Preparation (APF), which allows the maximum surprise effect. This is due to the fact that it has high accuracy and no verification firing is required.

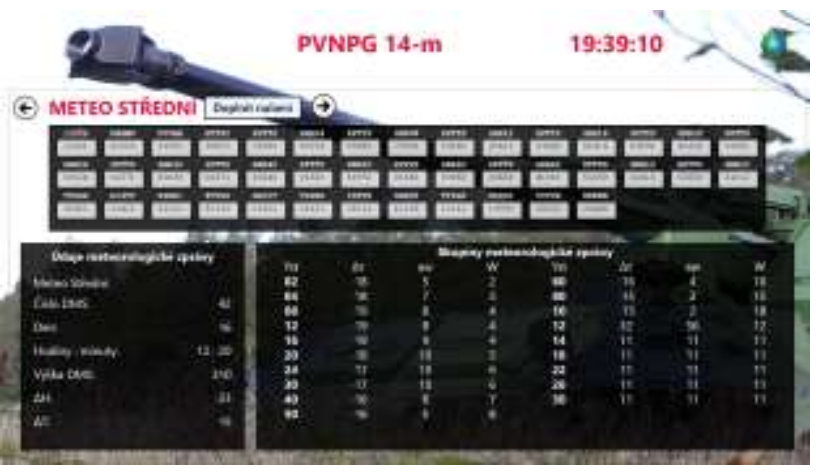

Fig. 9 Print Screen PVNPG-14M - Meteorological part 
In order to use this main method of determining the artillery fire elements for firing, it is necessary to include to the calculations various corrections, which are classified in several areas:

1. Topographical-geodetically preparation;

2. Reconnaissance and target detection;

3. Meteorological preparation (Fig. 9);

4. Ballistic preparation. [2] [9]

\section{B. Fictional auxiliary target creation - Registration fire}

The second way according to which it is not necessary to verification perform control firing is the transfer of fire from the fictional auxiliary targets (FPC). The accuracy of this method is also sufficient. The following restrictions are set for this method:

- the technical capabilities of the reconnaissance device must allow to observe the results of firing for FPC (Fig. 10);

- created corrections for transfer firing must be used for the same type of ammunition (same table corrections) when creating auxiliary targets as when firing at targets, both in the direction and in the distance of fire;

- the maximum time limit for the use of this method is set at 180 minutes from the first firing. [10] [10] [11]

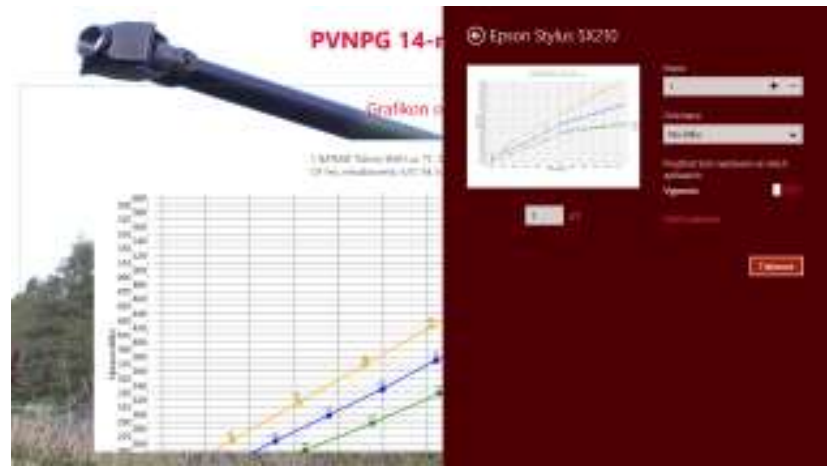

Fig. 10 Print Screen PVNPG-14M - Observing part

The Angular Artillery mil rule is the rule which is used by artillery and other commanders. The rule is inserted into the developed software tools (e.g. PVNPG-14M). In cases where it is not possible to use application tools, it is necessary to know the possibilities and limitations of using this artillery rule.

\section{CONCLUSION}

The limit values defined in this paper, under which it will be possible to use the artillery rule on the battlefield, were derived on the basis of formulas and calculations in specified ranges. In the coming period, more and more devices and weapons will be gradually introduced into the Army of Czech Republic, which use the artillery division of the circle into 6400 mils. This unit is standard for most
NATO countries. [12] [13]

In order for artillery commanders, as well as other commanders, to correctly use the artillery rule, they must know the essence of the artillery rule and its other restrictions and principles for its properly use. Such a restriction may be a restriction on the possibility to apply only up to the value of the angle $\alpha 100$ mils. In this case, a 2\% correction must be automatically taken into account.

The application of this rule to the new application support for commanders is a matter of course.

\section{ACKNOWLEDGMENT}

The work was supported by the Ministry of Education, Youth and Sports of the Czech Republic, project No. SV20_FVL-K107-ŠUS

\section{References}

[1] BLAHA, Martin, POTUŽÁK, Ladislav, ŠILINGER, Karel. Linear and Angular Issues in Perspective Artillery Fire Control System. In: 22nd International Conference on Circuits, Systems, Communications and Computers (CSCC 2018). Majorca, Spain: EDP Sciences, 2018. ISSN 2261-236X.

[2] BLAHA, Martin, ŠILINGER, Karel. Application support for topographical-geodetic issues for tactical and technical control of artillery fire. International Journal of Circuits, Systems and Signal Processing, 2018, (12), 48-57. ISSN 1998-4464.

[3] Jadranko Tuta, Ljerka Luić, Serious Games Communication Aspects of VR Cadet Training Information Model, WSEAS Transactions on Business and Economics, ISSN / E-ISSN: 1109-9526 / 2224-2899, Volume 17, 2020, Art. \#55, pp. 560-569.

[4] BLAHA, M., BRABCOVÁ, K. Decision-Making by Effective C2I system. In The 7th International Conference on Information Warfare and Security. Seattle (USA): Academic Publishing Limited, 2012, pp. 44-51. ISBN 978-1-908272-29-4.

[5] BLAHA, M., SOBARŇA, M. Some develop aspects of perspective Fire Support Control System in Czech Army conditions. In The 6th WSEAS International Conference on Dynamical Systems and Control. Sousse (Tunisia): University of Sfax, 2010, pp. 179 - 183.

[6] AAP-6 NATO Glossary of Terms and Definitions (english and french). 2009.

[7] DUBEC, Radek; HRŮZA, Petr. Military Concept of Modularity. Croatian Journal of Education, 2012, vol. 14, no. Spec.Ed. 1, p. 35-41. ISSN 1848-5189.

[8] MAJEK, V., SLOUF, V. Operations with fuzzy numbers in the task divided targets. In ICMT 2015 - International Conference on Military Technologies 2015, pp. 641-645.

[9] STODOLA, Petr; MAZAL, Jan. Model of Optimal Cooperative Reconnaissance and its Solution using Metaheuristic Methods. Defence Science Journal, 2017, vol. 67, no. 5, p. 529-535. ISSN 0011-748X. 
[10] STODOLA, Petr, VOJTEK, Jozef, KUTĚJ, Libor, NEUBAUER, Jiří. Modelling Militarized Interstate Disputes Using Data Mining Techniques: Prevention and Prediction of Conflicts. The Journal of Defense Modeling and Simulation: Applications, Methodology, Technology, 2020, 1-15. ISSN 1548-5129.

[11]PALASIEWICZ, Tibor; SKALICKÝ, Pavel; KYJOVSKÝ, Jan; ZELENÝ, Jaroslav. Possibilities of Modelling and Simulation in Military Engineering. In: Modelling and Simulation for Autonomous Systems. Cham: Springer, 2018, p. 402-409. ISSN 0302-9743. ISBN 978-3-319-76071-1.

[12] VLKOVSKÝ, Martin. Drivers Training based on Data from Accelerometer. International Jounal of Education and Information Technologies, 2020, 2020(14), 14-21. ISSN 2074-1316.

[13] ŠUSTR, Michal, POTUŽÁK, Ladislav, BLAHA, Martin, IVAN, Jan. Střelba s jednotným dopadem střel a možnosti využití v Armádě České republiky. Vojenské rozhledy, 2020, 2020(4/2020), 84-93. ISSN 1210-3292.

LTC Martin BLAHA, born 1983, graduate of the Faculty of Economics and Management of the University of Defence in Brno (Military Management field of study). He served at command and staff positions of artillery units in artillery regiment. Since 2008 he has been participating in the pedagogical and scientific activities of the Department of Fire Support at the University of Defense in Brno. In 2012, he completed his doctoral studies at the University of Defense, in the study program Economics and Management. He is currently the Acting Head of the Department of Fire Support of the University of Defense. He deals with the combat use of artillery, especially in the field of fire control and automation of fire control processes. [16]

Martin Blaha carried out the topic, software application and calculation.

Ladislav Potužák carried out the topic, introduction and calculation.

Michal Šustr has implemented the mathematic formula and calculation.

Jan Ivan has organized and executed the calculation of equitation errors.

Tomáš Havlík was responsible for the practicing and verification of mile rule.

\section{Creative Commons Attribution License 4.0 (Attribution 4.0 International, CC BY 4.0)}

This article is published under the terms of the Creative Commons Attribution License 4.0

https://creativecommons.org/licenses/by/4.0/deed.en US 